\title{
Performance of a cooling tower with the use of a new kind of high-density polyethylene (HDPE) packing
}

\author{
Nagam Obaid Kariem*, Mohammed A. Rasheed* and Zainab T. Al-Sharify*,**,*** \\ * Environmental Engineering Department, College of Engineering, Mustansiriyah University, Bab-al-Mu'adhem, Baghdad, Iraq \\ ** School of Chemical Engineering, University of Birmingham, Edgbaston, Birmingham, United Kingdom \\ *** Corresponding Author: z.t.alsharify@uomustansiriyah.edu.iq
}

Submitted : 30/04/2020

Revised : :13/05/2021

Accepted : 19/05/2021

\begin{abstract}
This research work deals with the performance of high-density polyethylene sheets arranged in splash used as a fill for a cooling tower. "A forced-draught counterflow cooling tower" of $400 \mathrm{~mm} \times 400 \mathrm{~mm}$ cross-sectional area and $1.7 \mathrm{~m}$ in height was built. The fill has been studied theoretically and experimentally. Air rates of $0.6,1.2$, and 1.8 $\mathrm{kg} / \mathrm{s} . \mathrm{m} 2$ were utilized with water flow rates within the range of 1 to $1.6 \mathrm{~kg} / \mathrm{s} \cdot \mathrm{m}^{2}$. The overall volumetric heat transfer coefficient, volumetric mass transfer coefficient $(M t)$, and the tower characteristics $(M t / L)$ are shown to be functions of the air and water flow rates concurrently. Four available input parameters were inlet water temperature, airflow rate, water flow rate, and full height. A computer program was prepared to perform numerical analysis for reducing data sets obtained from the plant. In addition, analysis was carried out for evaluating the volumetric heat and mass transfer coefficients along with the performance coefficient.
\end{abstract}

Keywords: Cooling tower; Polyethylene; Mass transfer coefficient; Heat transfer; Screw HDPE packing.

\section{NOMENCLATURE}

A Cross-sectional area, $\mathrm{m}^{2}$

B Dimensional constant

G Airflow rate, $\mathrm{kg} / \mathrm{s} . \mathrm{m}^{2}$

$H t \quad$ Heat transfer coefficient, $\mathrm{kW} / \mathrm{m}^{2} . \mathrm{k}$

$L \quad$ Water flow rate, $\mathrm{Kg} / \mathrm{s} . \mathrm{m}^{2}$

Mt Mass transfer coefficient, $\mathrm{kg} / \mathrm{s} . \mathrm{m}^{2}$ 


\author{
Hgl Enthalpy of air at the tower outlet, $\mathrm{kJ} / \mathrm{kg}$ dry air \\ $\mathrm{Hg} 2 \quad$ Enthalpy of air at the tower inlet, $\mathrm{kJ} / \mathrm{kg}$ dry air \\ Z Fill height $\mathrm{m}$.
}

\title{
INTRODUCTION
}

A cooling tower is a machine that eliminates waste heat to the environment by acting as a heat rejection device. Heat elimination is achieved by cooling a stream of water at lower temperatures. A cooling tower is a machine in which water and air are in direct contact. The function of this machine is to reduce the temperature of the water $(\mathrm{Li}$ et al., 1997; Murtadah et al., 2020; Al-Moameri et al., 2021)). Such cooling towers can work in two ways. Firstly, in cases of closed-circuit, these dry towers depend merely on the air for cooling the operational fluid to approximate to the "dry-bulb air temperature." Otherwise, some cooling towers may use the water evaporated for removing the heat accumulated in the process and for cooling the operational fluid to approximate the "wet-bulb air temperature" (Shah, 2016, Ma et al., 2018).

Mostly, cooling towers are used in the heating, ventilation, and air conditioning (HVAC) systems where pipes supply warm water to the cooling tower (García, 2017, Al-Moameri et al., 2019). In cooling towers, water is splashed by nozzles. The filling material inside the tower increases the surface area, and the air comes in contact with water. The air exchange heat and the water is cooled. The laboratory cooling tower is usually set with an air conditioning system. In this system, the water heater is set, and the cooling tower is used to cool water. A fan is used to provide air to the hot water, and the pump is installed to supply cooled water to the water heater (Tomberlin et al., 2018, Afshari and Dehghanpour, 2019). Water from the heater moves towards the cooling tower and is collected in the reservoir. Next, the water is sprayed over the area of the tower. The function of the reservoir is to provide extra water lost in the process of evaporation, and in this way, the level of water is maintained.

In recent years, the authors concluded that the efficiency of the cooling tower depends on many factors such as packing (Al-Sharify et al, 2009; Abidzaid, 2010; Latif, 2012). In Ragupathy study, the researchers investigated the thermal performance of a "forced-draught counterflows wet cooling tower" experimentally. The tower had a packing of expanded wire mesh kind. Such a kind had horizontal as well as vertical orientations. The experiments determined that the cooling tower performance was enhanced with the vertical orientation of the packing.

Lavasani et al. (Lavasani et al., 2014, Al-Moameri et al., 2020) applied a numerical integration method for calculating the thermal characteristics of the tower. Kelly and Swenson (Kelly, 1956, Al-Moameri et al., 2020) showed that the tower characteristic or temperature increases. They made a series of runs in which the hot water temperature varied from $100^{\circ} \mathrm{F}$ to $150^{\circ} \mathrm{F}$, at constant $L$, packed height, and wet bulb temperature. In their study, they also found that the overall tower characteristics $(M t / L)$ can be expressed as the sum of the values of the $(M t / L)$ for the end effects and the packed section, as follows:

$(\mathrm{Mt} / \mathrm{L})_{\mathrm{total}}=(\mathrm{Mt} / \mathrm{L})_{\mathrm{ends}}+(\mathrm{Mt} / \mathrm{L})_{\text {fill }}$

For their investigation, they found that

$(\mathrm{Mt} / \mathrm{L})=0.007+\mathrm{A}+\mathrm{N} *(\mathrm{~L} / \mathrm{G})$.

where $A$ and $N$ are constants depending on the type of deck. 
Overall, HDPE is used to construct a cooling tower in terms of the fills as it is an optimum material. The sheets are produced, and there is no requirement for joints and bolts. Thus, the chances of a leak are reduced to zero levels. Also, the chances of rust and crack are reduced. The comparison of different types of cooling tower portrays the following noticeable points:

- Galvanized towers are corrosion-free.

- Zinc galvanized towers have an advantage that delays the corrosion further.

- HDPE towers are energy efficient, and minimum maintenance is required. Water conservation and sustainability also make them unique from others. HDPE is strong, dense, and stiff and has a crystalline structure. It is easy to clean, corrosion-resistant, and eco-friendly.

The construction of a typical cooling tower involves several steps ranging from the casing, then fill to the flow type.

For the casing, selecting an appropriate material in the construction of the cooling tower is extremely important. The main purpose of the casing is to reduce maintenance needs and ensure the longevity of the tower with reliability. Galvanized steel, stainless steel, concrete, and fiberglass are the most common material used for casing. However, casings are usually made of glass fiber as it protects the tower from chemicals.

As discussed previously, the use of PVC, polymers, and polypropylene is common for the fill material in the tower. In some countries, the fill is made of wood. However, the wood is still in use; it was found that the plastic fill has a greater heat transfer capacity. Also, the fill may result in either crossflow or counterflow (Gharagheizi et al., 2007; Kariem et al., 2020). In crossflows, the air and water meet crossly. The air is allowed to enter from both sides, while the warm water enters from the top. The cold-water leaves from the bottom. For the counterflow, there is a counterflow between air and water. The water is scattered over the fill, and the cold water leaves from the bottom (Mohiuddin and Kant, 1996).

In terms of the calculations, there are many small instruments used to calculate cooling towers' performance. The required parameters are water flow rate, air flow rate, inlet and outlet water temperatures, and dry bulb and wet bulb temperatures of air. In evaluating performance, the approach adopted, the range, and corresponding efficiencies of the system are extremely important. To be able to calculate the above parameters, we used the following correlations:

$$
\begin{gathered}
\text { Approach }=\text { Cold water temperature }- \text { wet bulb temperature } \\
\text { Range }=\text { Hot water temperature }- \text { Hot water temperature } \\
\text { Efficiency }=\left(\frac{\text { Range }}{\text { Range }+ \text { Approach }}\right) \times 100
\end{gathered}
$$

The liquid/gas ratio is a ratio between the water and air mass flow rates. Some changes are usually required to improve results, so adjustments are done in water loading and fan blade angle. In thermodynamics, it is a fundamental rule that the heat absorbed by air must be equal to the heat rejected by the water. Usually, the notations involve $L$ being referred to as the water flowrate and $\mathrm{G}$ as the gas flowrate (Mohiuddin and Kant, 1996, Rzaij et al., 2020). 


\section{APPARATUS AND EXPERIMENTAL PROCEDURE}

As illustrated in Figure 1, a mechanical forced-draught counterflow cooling tower was constructed. A certain way was chosen for the arrangement of the tower to provide maximum possible access to the section of the tower. The maximum access of heat exchange is solely done for smoothing the process of maintenance and observation without impeding operations. The instruments and equipment were systematically assembled to ensure that the energy and material balances could be accomplished readily.

In a closed system, water circulation was preserved during a run. With a centrifugal pump, the water from the $2 \times 2 \times 1.65 \mathrm{ft}$ tower basin is pumped. Next, the water passed through the constant vessel tank. The water flow circulation results in the provision of a steady-state head. The water then passes to the water heating tank made of stainless steel, with $6 * 2.5 \mathrm{KJ} / \mathrm{s}$ (240 volts) immersion elements. Then, the water passed towards the main area of the tower distribution.

Distribution of water on the fills' upper edge was made possible using 14 P.V.C tubes with a $10 \mathrm{~mm}$ diameter. Each tube had 14 holes, was $2.5 \mathrm{~mm}$ in diameter, and ensured the film flow of the water. Next, the water flow rates were assessed using a rotameter, which was independently calibrated. Overall, the tower was $400 \mathrm{~mm}$ by $400 \mathrm{~mm}$ in cross-section. The difference between the inlet air distributor and water distributor was $1.4 \mathrm{~m}$. Also, the front side of the tower was made of a moving plastic sheet.

From the bottom of the tower, the air entered and traveled thru the packing from slot entry. It must be noted that such an assembly results in a counter-current flow between the upward air and the falling water inside the tower. Furthermore, to control evaporation, a porous plastic pad, mist eliminator was positioned above the water distribution system in the tower. The air supply to the system was provided using a fan. The air volume flow rates were measured by using a U-manometer.

It is worth mentioning that, in the cooling tower, the heat transfer factor was the fill, made from HDPE, as shown in Figure 2. Different heights of packing used were 25, 50, 75, and $100 \mathrm{~cm}$, according to the tests carried out. These heights were chosen to assess the end effects specifically. Moreover, the distance between the top of the fill and the tubes for water distribution was maintained at $4 \mathrm{~cm}$ to avoid splashing. Eleven calibrated thermocouples were used for measuring water and air temperatures. These were situated systematically and allowed for determining the air or water's weighted average temperature at all points. Also, a single thermocouple was used for measuring the inlet water temperature.

Table 1 details the measured variables and the corresponding thermocouple codes.

Table 1. The measured variables.

\begin{tabular}{|l|c|c|}
\hline \multicolumn{1}{|c|}{ Temperature } & \multicolumn{2}{c|}{ Thermocouple code } \\
\hline Intel water temperature & 2 & 3 \\
\hline Outlet air dry bulb temperature & 4 & 5 \\
\hline Outlet air wet bulb temperature & 6 & 7 \\
\hline Outlet water temperature & 8 & 9 \\
\hline Inlet air dry bulb temperature & 10 & 11 \\
\hline Inlet air wet bulb temperature & & 1 \\
\hline
\end{tabular}




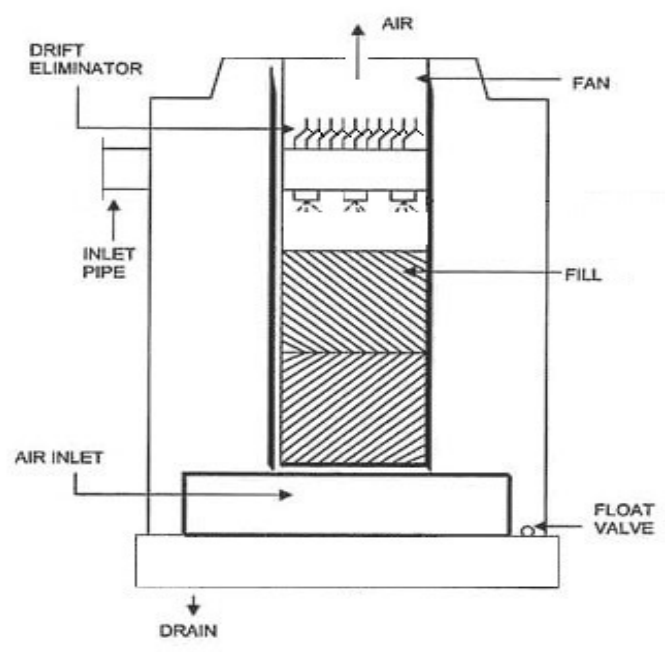

Figure 1. Schematic diagram of the cooling tower.

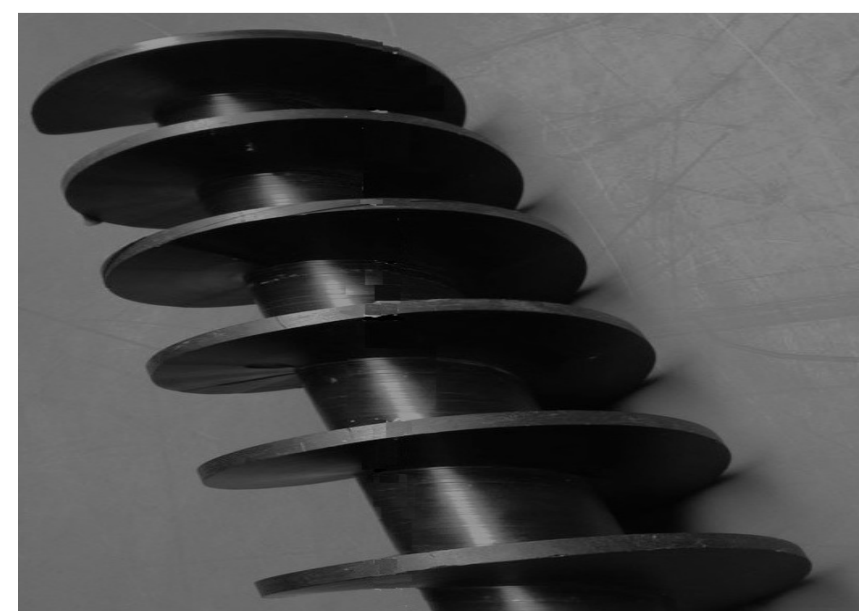

Figure 2. Screw HDPE packing.

\section{RESULTS AND DISCUSSION}

The tower characteristics $(M t / L)$ are shown in

Figure 3 to Figure 6 . These figures show plots of the tower's characteristics; the water to air ratio values $(L / G)$, for HDPE, fill at heights of $25,50,75$, and $100 \mathrm{~cm}$, respectively, and nominal inlet water temperature $\left(t_{12}\right)$ at $45^{\circ} \mathrm{C}$.

The results show that nearly parallel and straight lines are enough to fit the data mentioned above. The above result was also addressed and reported by other authors.

The results showed that, at constant air flux $G$, an increase in the water to air ratio leads to a decrease in the characteristics of the tower. The point can explain such behavior that increases in water flux, $L$, at a constant $G$, result in increases in heat load, which sequentially decreases the filling ability for the excess heat load dissipation. 


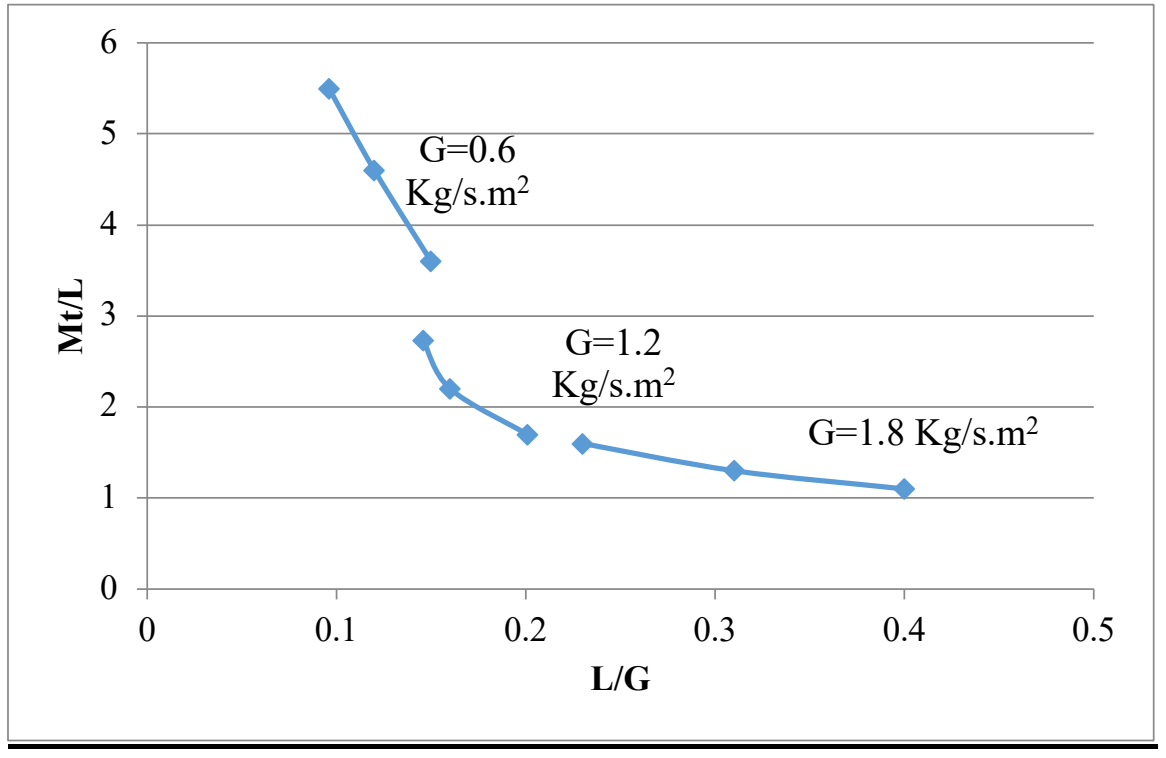

Figure 3. Uncorrected $\mathrm{Mt} / \mathrm{L}$ vs. $\mathrm{L} / \mathrm{G}$ for Screw packing at $\mathrm{TL}=45^{\circ} \mathrm{C}, \mathrm{Z}=25 \mathrm{~cm}$.

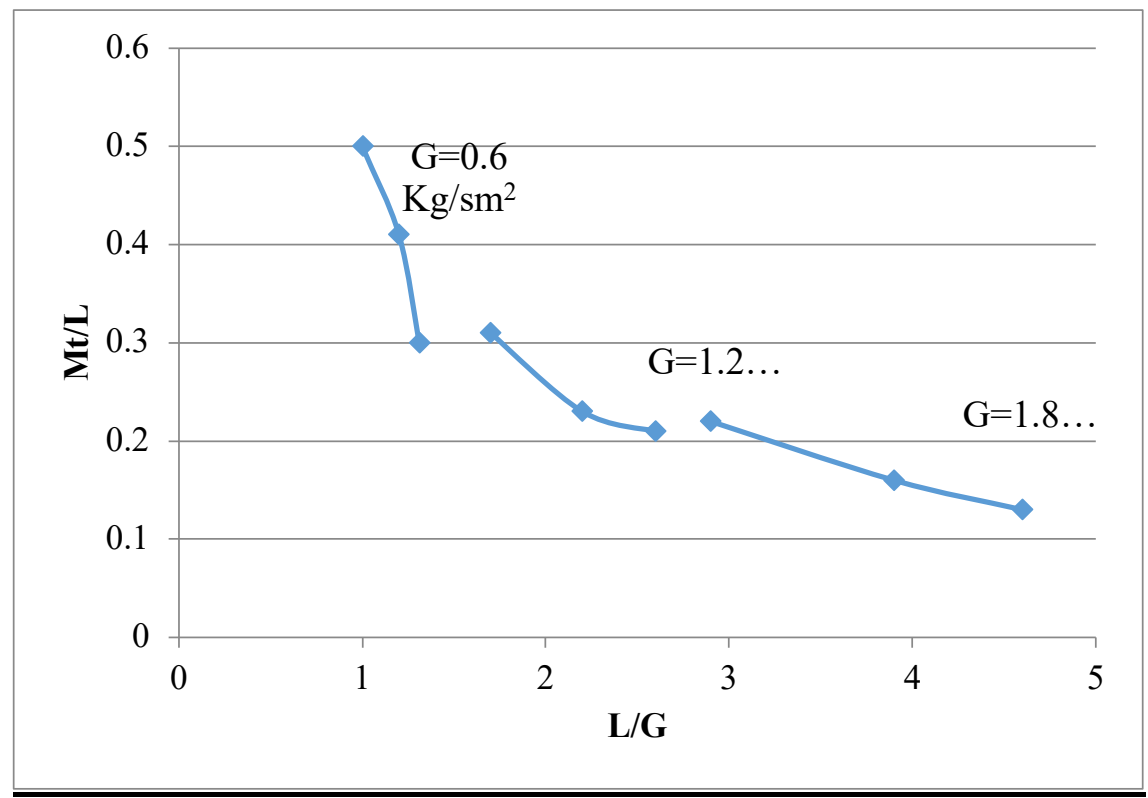

Figure 4. Uncorrected $\mathrm{Mt} / \mathrm{L}$ vs. $\mathrm{L} / \mathrm{G}$ for Screw packing at $\mathrm{TL}=45^{\circ} \mathrm{C}, \mathrm{Z}=50 \mathrm{~cm}$. 


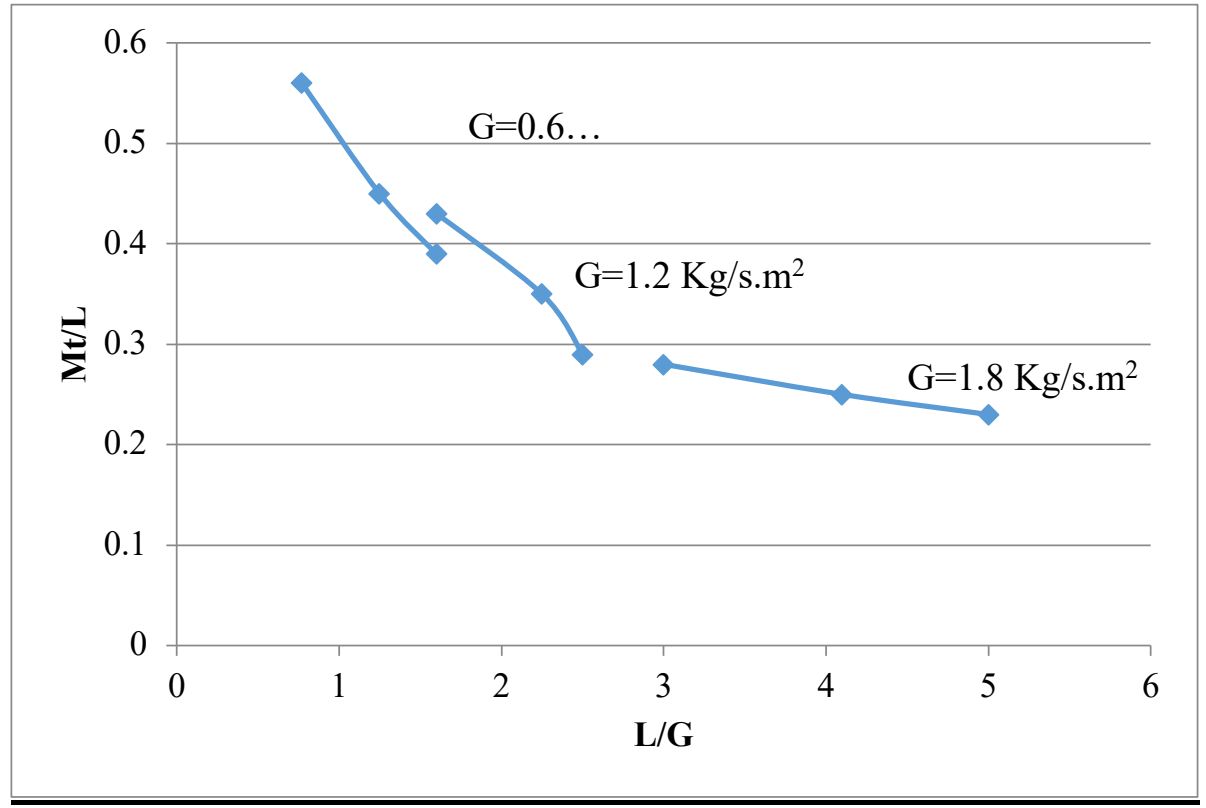

Figure 5. Uncorrected $\mathrm{Mt} / \mathrm{L}$ vs. $\mathrm{L} / \mathrm{G}$ for Screw packing at $\mathrm{TL}=45^{\circ} \mathrm{C}, \mathrm{Z}=75 \mathrm{~cm}$.

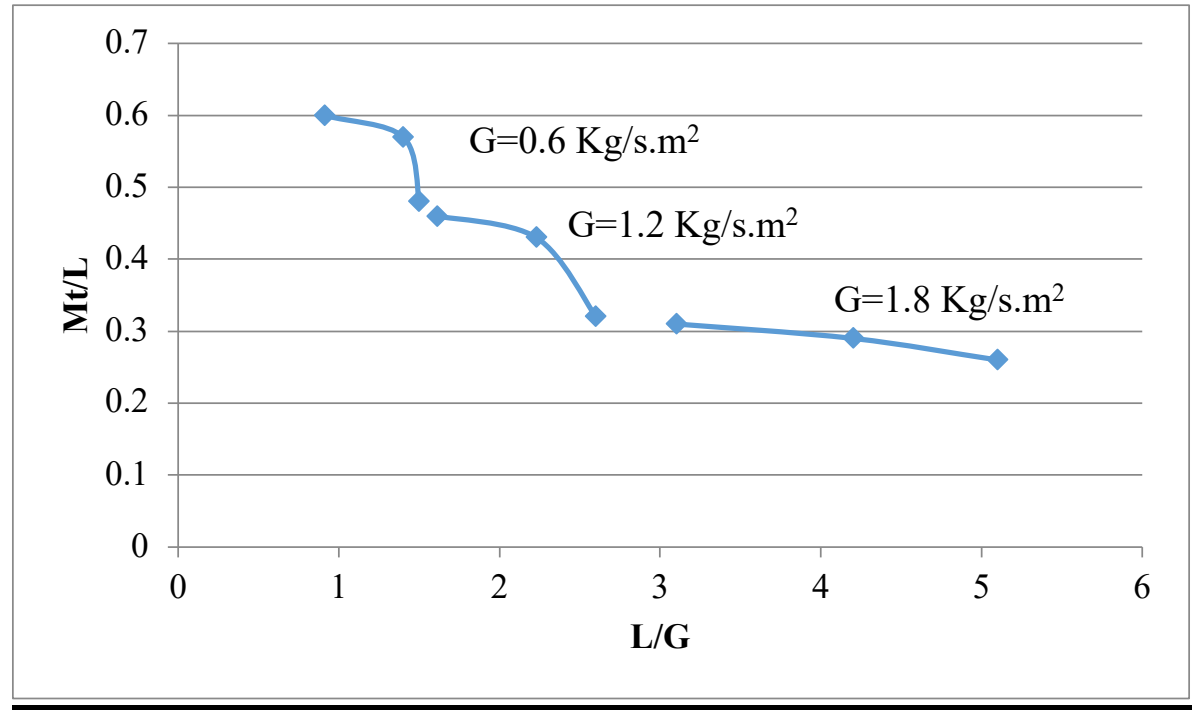

Figure 6. Uncorrected $\mathrm{Mt} / \mathrm{L}$ vs. $\mathrm{L} / \mathrm{G}$ for Screw packing at $\mathrm{TL}=45^{\circ} \mathrm{C}, \mathrm{Z}=100 \mathrm{~cm}$.

The effect of the inlet water temperature is illustrated in Figure 7 on the tower characteristics. The figure indicates that tower characteristics decrease with increases in the inlet water temperature for the constant value of water: air ratio $(L / G)$. Such a finding proves that increases in heat loads decrease the characteristics of the tower. Moreover, the results from the experiments revealed that a decrease in $M t / L$ amounted to about $6 \%$ for each $5 \circ \mathrm{C}$ rise in the water temperature at the inlet. 


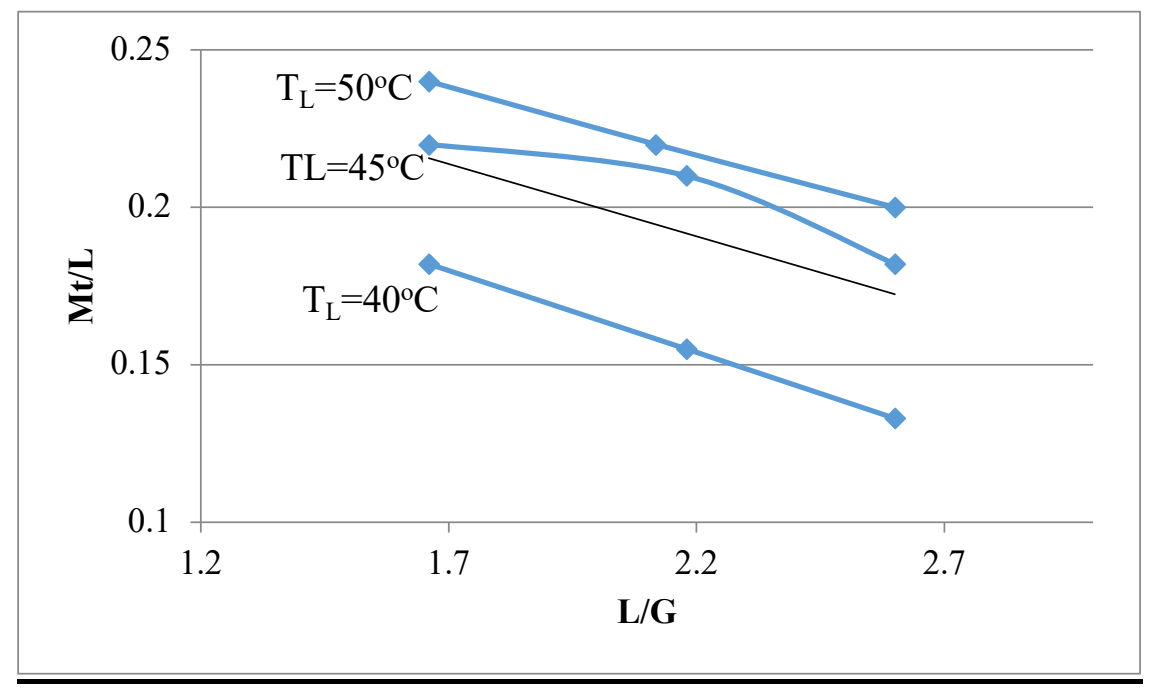

Figure 7. Uncorrected $M t / L$ vs. $L / G$ for Screw packing at $Z=25 \mathrm{~cm}$ and $\mathrm{G}=0.6 \mathrm{Kg} / \mathrm{s} . \mathrm{m}^{2}$.

Figure 8 shows the effects of the water temperature at the inlet corresponding to the air flux, G, on the volumetric mass transfer coefficient $(M t)$. Based on these results, potential decreases in $M t$ occur due to an increase in the inlet water temperature. As demonstrated in Figures 5 and 6, this is mainly because of reducing the tower characteristics $M t / L$. In contrast, increases in air flux from 1.2 to $1.8 \mathrm{Kg} / \mathrm{s} \cdot \mathrm{m}^{2}$ increase $M$ by about $16 \%$. The increase in $\mathrm{M}$ is sole since the evaporation rate is directly related to the air rate.

Figure 9 shows the impact of the inlet water temperature and air flux, $G$, on the volumetric heat transfer coefficient $(H t)$. The impact is similar to the impact on $M t$. This is whole since the subsequent calculations were made using the Lewis relationship (equation 4):

$\mathrm{Ht}=\mathrm{Mt} . \mathrm{C}_{\mathrm{s}}$

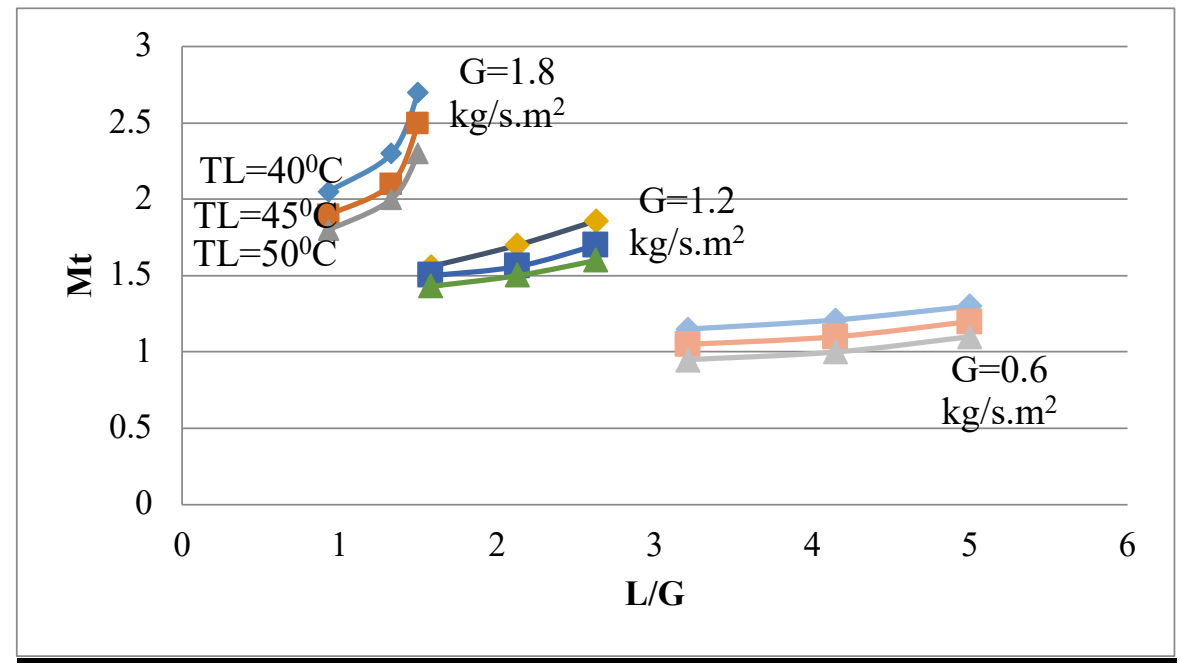

Figure 8. Volumetric mass transfer coefficient vs. $L / G$ for screw packing and $Z=60 \mathrm{~cm}$. 


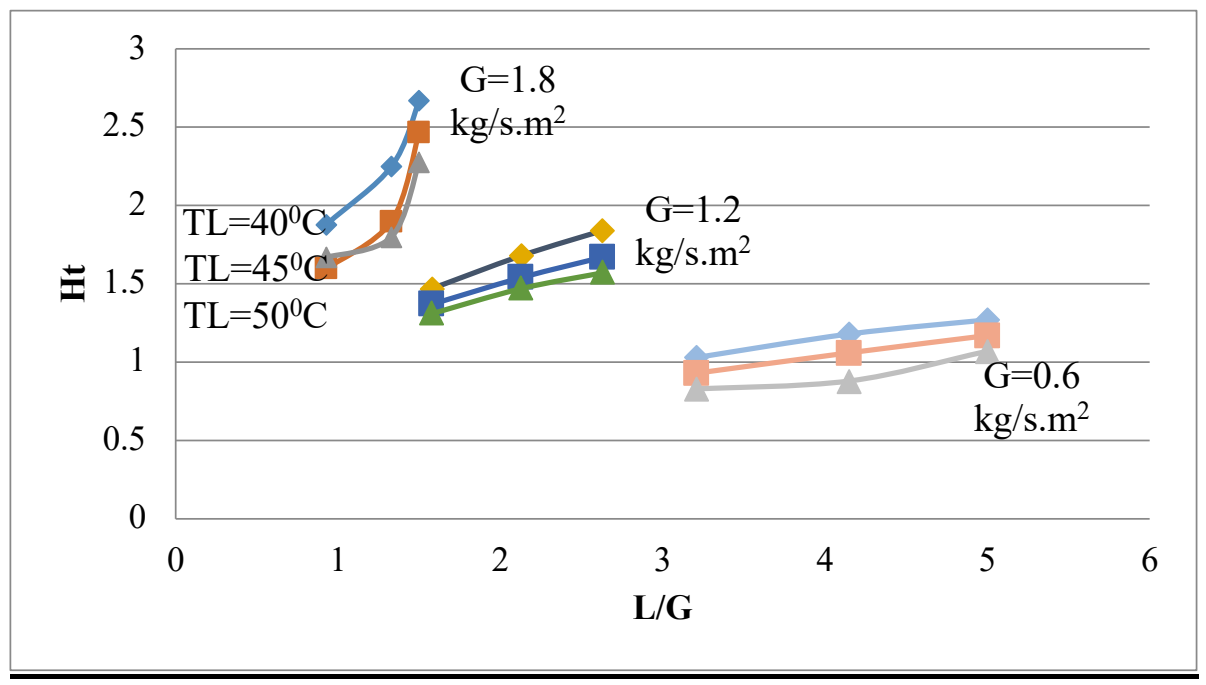

Figure 9. Volumetric heat transfer coefficient vs. $\mathrm{L} / \mathrm{G}$ for screw packing and $\mathrm{Z}=60 \mathrm{~cm}$.

Comparisons between the tower characteristics $(M t / L)$ in different packed heights for HDPE fill (tL2 $=313 \mathrm{k}$ ( 40 0C ) ) for uncorrected height due to the endpoint are shown in Table 2. Also, the literature reports that several researchers in the same fields have attempted to correlate $\mathrm{L} / \mathrm{G}$ with tower characteristics. The formulae of type in equation (5) are widely utilized to estimate the air and constant $\mathrm{cm}$ tower characteristics.

$$
M t=c(L / G)^{m}
$$

With a constant air flux, G, the magnitude of end effects is tested and determined at numerous heights. Upon extrapolation to 0 height, the characteristic tower value for end effects is achieved. Thus, the value of the $M t / L$ equation can be achieved by intercepting the vertical axis. Also, corresponding to the end effects, the number of transfer units can also be attained. These can be subtracted from the uncorrected tower characteristics $(M t / L)$. On the contrary, the horizontal axis intercept corresponds to the (-) value of Zeq, which is the end effects' equivalent height.

Again, the tower characteristics $M t / L$ at various packed elevations are compared, following the exclusion of the end effects' values. The correlations are listed in Table 3. The tested data correlation comprises understanding the fundamental curve, which agrees with all other curves while considering $L$ as well as $G$ independently for accounting the air flux variation as follows:

A $1.1 \%$ probability is associated with the expected error. Also, with each correlation, a similar term will be associated (see eq. 6).

$$
M t=0.671(L)^{-0.76}(G)^{0.55}
$$


Table 2. Comparisons between the tower characteristics $(\mathrm{Mt} / \mathrm{L})$ in different packed heights for HDPE fill for uncorrected height.

\begin{tabular}{|c|l|}
\hline Height (cm) & Uncorrected Correlations \\
\hline 100 & $\mathrm{Mt}=0.633(\mathrm{~L} / \mathrm{G})-0.553$ \\
\hline 75 & $\mathrm{Mt}=0.547(\mathrm{~L} / \mathrm{G})-0.513$ \\
\hline 50 & $\mathrm{Mt}=0.461(\mathrm{~L} / \mathrm{G})-0 . .456$ \\
\hline 25 & $\mathrm{Mt}=0.376(\mathrm{~L} / \mathrm{G})-0.366$ \\
\hline 100 & $\mathrm{Mt}=0.633(\mathrm{~L} / \mathrm{G})-0.824$ \\
\hline 75 & $\mathrm{Mt}=0.563(\mathrm{~L} / \mathrm{G})-0.808$ \\
\hline 50 & $\mathrm{Mt}=0.713(\mathrm{~L} / \mathrm{G})-0.825$ \\
\hline 25 & $\mathrm{Mt}=0.416(\mathrm{~L} / \mathrm{G})-0.727$ \\
\hline 100 & $\mathrm{Mt}=0.686(\mathrm{~L} / \mathrm{G})-0.447$ \\
\hline 75 & $\mathrm{Mt}=0.711(\mathrm{~L} / \mathrm{G})-0.807$ \\
\hline 50 & $\mathrm{Mt}=0.512(\mathrm{~L} / \mathrm{G})-0.561$ \\
\hline 25 & $\mathrm{Mt}=0.417(\mathrm{~L} / \mathrm{G})-0.617$ \\
\hline
\end{tabular}

Table 2. Corrected Correlations.

\begin{tabular}{|c|l|}
\hline Height (cm) & Corrected Correlation \\
\hline 100 & $\mathrm{Mt}=0.422(\mathrm{~L} / \mathrm{G})-0.766$ \\
\hline 75 & $\mathrm{Mt}=0.347(\mathrm{~L} / \mathrm{G})-0.698$ \\
\hline 50 & $\mathrm{Mt}=0.285(\mathrm{~L} / \mathrm{G})-0.622$ \\
\hline 25 & $\mathrm{Mt}=0.135(\mathrm{~L} / \mathrm{G})-0.751$ \\
\hline 100 & $\mathrm{Mt}=0.551(\mathrm{~L} / \mathrm{G})-0.801$ \\
\hline 75 & $\mathrm{Mt}=0.561(\mathrm{~L} / \mathrm{G})-0.917$ \\
\hline 50 & $\mathrm{Mt}=0.322(\mathrm{~L} / \mathrm{G})-0.89$ \\
\hline 25 & $\mathrm{Mt}=0.317(\mathrm{~L} / \mathrm{G})-0.77$ \\
\hline 100 & $\mathrm{Mt}=0.505(\mathrm{~L} / \mathrm{G})-0.635$ \\
\hline 75 & $\mathrm{Mt}=0.377(\mathrm{~L} / \mathrm{G})-0.592$ \\
\hline 50 & $\mathrm{Mt}=0.295(\mathrm{~L} / \mathrm{G})-0.501$ \\
\hline 25 & $\mathrm{Mt}=0.263(\mathrm{~L} / \mathrm{G})-0.631$ \\
\hline
\end{tabular}




\section{CONCLUSION}

It is apparent from the research work that using minimum water and airflow ratio, $L / G$, allows for achieving the maximum performance in a given volume of tower fill. The "Least square method" was employed for correlating the experimental results, where the dependent variable $(M t / L)$ correlated with water and airflow ratio $(L / G)$ by fitted log$\log$ data. Also, the exponents of the equation lied in the range between -0.40 and -0.81 . Finally, the end effects involve open space on top of the fill and the open space beneath the fill, where a certain amount of cooling took place in these zones. Thus, a parametric study for HDPE fills material was conducted, which assisted in the estimation of the tower characteristics in terms of such effects regarding the corrected value. The results (correlation equation per unit depth of fill height) are provided as the individual volumetric coefficient of heat and mass transfer $(\mathrm{Ht}$, and $\mathrm{Mt}$ ), which were observed to be influenced merely by the variables in the system, for instance, the inlet water temperature and the air and water fluxes. The following equation can be utilized in this context. In future works, it is recommended to develop a computer simulation for the performance of the cooling tower.

$M t=0.671 L^{-0.7} G^{0.53}$

\section{ACKNOWLEDGMENT}

The authors would like to thank Mustansiriyah University (www.uomustansiriyah.edu.iq), Baghdad, Iraq, for its support in the present work.

\section{REFERENCES}

Afshari, F. \& H. Dehghanpour, 2019. A Review Study On Cooling Towers; Types, Performance and Application. ALKÜ Fen Bilimleri Dergisi, 1-10.

Al-Moameri, H., G. Hassan \& B. Jaber, 2019. Simulation Physical and Chemical Blowing Agents for Polyurethane Foam Production. IOP Conference Series: Materials Science and Engineering - 2nd International Conference on Sustainable Engineering Techniques, ICSET 2019, Institute of Physics Publishing.

Al-Moameri, H., L. Jaf \& G. J. Suppes, 2021. "Simulation approaches for the mechanisms of thermoset polymerization reactions." Molecular Catalysis 504: 111485.

Al-Moameri, H. H., M. A. Abdulrehman \& I. I. Marhoon, 2020. "The Optical, Structural and Thermal Properties of Transparent Poly (Methylmethacrylate)/Cellulose Acetate Phthalate Blend." Defect and Diffusion Forum 398: 98-105.

Al-Moameri, H. H., N. T. Al-Sharify, M. A. Abdulrehman \& Z. T. Al-Sharify, 2020. "Impact of nanoparticles on polyurethane resin's final properties." Journal of Green Engineering 10(6): 3114-3126.

Abidzaid, Z. T., 2010. "Modified Equations for Water Flow through Packed Bed for different types of packing systems". Journal of Al-Rafidain University 26: 35-53.

Latif, M. N., Abd Al-Wahed, W., \& Abidzaid, Z. T., 2012. ' 'Experimental Study of Fluid Flow Through Packed Beds of Glass Sphere Packing'’. University of Thi-Qar Journal for Engineering Sciences, 3(2) : 32-47.

Al-Sharify, T. A., Al-Sharify, Z. T. A., \& Abass, M. N 2009. "Modification of Porosity Equation for Water Flow through Porous Media." Journal of Environmental studies,Sohag University, Egypt. Vol. 2, pp. 65- 72.

Gharagheizi, F., R. Hayati \& S. Fatemi, 2007. "Experimental study on the performance of mechanical cooling tower with two types of film packing." Energy Conversion and Management 48(1): 277-280. 
Kariem, N.O., Mousa Al-Zobai, K.M., Al-Sharify, Z.T., 2020. 'Performance of cooling tower using sustainable polymers packing'’. Journal of Green Engineering, 10 (9), pp. 6871-6884.

Kelly, N., \& Swenson, L. K., 1956. "Comparative performance of cooling tower packing arrangements". Chemical Engineering Progress, 52(7).

Lavasani, A., Z. Baboli, M. Zamanizadeh \& M. Zareh, 2014. "Experimental study on the thermal performance of mechanical cooling tower with rotational splash type packing." Energy Conversion and Management 87: $530-538$.

Ma, L. B., Ren, J. X., Li, F. Q., Zhang, L. J., \& Li, M. Q. 2018. "The discussion on cooling optimization of natural draft wet cooling tower. In IOP Conference Series: Earth and Environmental Science 199: 032074.

Murtadah, I., Al-Sharify, Z. T., \& Hasan, M. B., 2020. 'Atmospheric Concentration Saturated and Aromatic Hydrocarbons Around Dura Refinery''. IOP Conference Series: Materials Science and Engineering Vol. 870, No. 1, p. 012033.

García Cutillas, C., Ruiz Ramírez, J., \& Lucas Miralles, M. , 2017. Optimum design and operation of an HVAC cooling tower for energy and water conservation. Energies, 10(3), 299.

Mohiuddin, A. K. M. \& K. Kant, 1996. "Knowledge base for the systematic design of wet cooling towers. Part I: Selection and tower characteristics." International Journal of Refrigeration 19(1): 43-51.

Rzaij, D. R., H. J. Al-Jaaf, S. Z. Al-Najjar, Z. T. Al-Sharify, H. H. Al-Moameri \& N. A. Mohammed, 2020. Studying the concentrations of nitrite and nitrate of Tigris river water in Baghdad and their suitability to the conditions permitted internationally. 1st International Conference on Engineering and Advanced Technology, ICEAT 2020, Institute of Physics Publishing.

Shah, U. S. M. K. A. P. D., 2016. "A review in design and performance analysis of cooling tower." International Research Journal of Engineering and Technology (IRJET) 3(12).

Tomberlin, G. R., Dean, J. D., \& Deru, M., 2018. Electrochemical Water Treatment for Cooling Towers (No. NREL/TP-7A40-72152). National Renewable Energy Lab.(NREL), Golden, CO (United States). 